\title{
Jogos, Adaptabilidade e Cognição: Uma Plataforma para Potencializar Jovens com Transtorno do Desenvolvimento
}

\author{
Mariza de Souza Moura ${ }^{1,2}$, Francisco Milton Mendes Neto ${ }^{1,2,3}$, Karla Rosane do \\ Amaral Demoly ${ }^{3}$, Everton Jales de Oliveira ${ }^{2}$, Rafael de Almeida Rodrigues ${ }^{2}$, \\ Ramiro de Vasconcelos dos Santos Junior ${ }^{2}$
}

${ }^{1}$ Programa de Pós-Graduação em Ciência da Computação - Universidade do Estado do Rio Grande do Norte (UERN) e Universidade Federal Rural do Semi-Árido (UFERSA) - RN, Brasil.

${ }^{2}$ Laboratório de Engenharia de Software - Universidade Federal Rural do Semi-Árido (UFERSA) CEP 59.625-900 - Mossoró - RN - Brasil.

${ }^{3}$ Programa de Pós-Graduação em Cognição, Tecnologias e Instituições, Departamento de Agrotecnologia e Ciências Sociais - Universidade Federal Rural do Semi-Árido (UFERSA) - RN, Brasil

\{marizasouzamoura, miltonmendes, karla.demoly, verto.jales
@gmail.com, rafael_allx@hotmail.com, ramirojuniordoutlook.com

\begin{abstract}
The extension program "Oficionados Network in Health", developed by a group of researchers, scholars and volunteers of the Federal Rural University of Semi-Arid (UFERSA) brought several opportunities for insertion of digital games in the activities of Psychosocial Care Center for Children and Teenagers of Mossoró/RN (CAPSi) and as a young man uses the game, their cognition movements are monitored, ie their ways to coordinate behavior in interaction with the game. From an analysis of ways to coordinate gestures, actions and emotions in the use of games, the idea of developing a platform containing games with adaptive features on individual characteristics presented by the youngs inserted into the CAPSi.
\end{abstract}

Resumo. O programa de extensão Rede de Oficinandos na saúde, desenvolvido por uma equipe de professores, bolsistas e voluntários da Universidade Federal Rural do Semi Árido (UFERSA) trouxe várias oportunidades para inserção de jogos digitais nas atividades do Centro de Atenção Psicossocial da Infância e da Adolescência de Mossoró/RN (CAPSi) $e$, à medida que um jovem utiliza o jogo, é acompanhado os movimentos da cognição, isto é, os modos de coordenar condutas na interação com o jogo. A partir de uma análise dos modos de coordenar gestos, ações e emoções no uso de jogos, surgiu a ideia de se desenvolver uma plataforma contendo jogos com funcionalidades adaptativas às características individuais apresentadas pelos jovens inseridos no CAPSi.

\section{Introdução}

A experiência em oficinas utilizando jogos digitais com jovens que apresentam transtornos de desenvolvimento e/ou sofrimento psíquico permite, colocar algumas questões, como, por exemplo: Como jovens deslocam e/ou transformam processos cognitivos e afetivos na experiência e interação com jogos digitais? Qual a vantagem ou melhoria que se tem a partir dos jogos utilizados com pessoas que apresentam 
transtornos mentais? Essas perguntas desencadeiam uma reflexão sobre como acontece a experiência humana nas dimensões cognitiva, técnica e social que a configuram e sobre o deslocamento e transformações cognitivas que acontecem no contato com a tecnologia e dos jogos digitais.

$\mathrm{Na}$ busca de entendimento sobre como os jogos podem favorecer processos cognitivos e afetivos na experiência dos jovens com transtornos de desenvolvimento, foram feitos estudos junto ao programa de extensão Rede de Oficinandos na Saúde', onde implementamos oficinas de jogos para observar e analisar modos de coordenar condutas, as ações jovens na interação com jogos em um ambiente equipado no Centro de Atenção Psicossocial da Infância e da Adolescência de Mossoró/RN (CAPSi). A perspectiva de análise de coordenação de condutas encontramos nos estudos da Cognição de Maturana e Varela (2001), cientistas que, ao estudarem processos perceptivos na experiência humana esclarecem que tudo o que nós os seres humanos produzimos ocorre na linguagem nas coordenações de coordenações de ações que estabelecemos no transcurso da experiência, processo este que se configura no entrelaçamento entre linguagens e emoções. Para compreender, portanto, como jovens com transtorno no desenvolvimento experimentam processos cognitivos e afetivos interagindo com jogos digitais, passamos a registrar modos de coordenar ações, reações, gestos, ideias, emoções durante oficinas semanais no CAPSi.

O acompanhamento dos modos de coordenar condutas na interação de jovens em oficinas de jogos digitais, permitiu, não somente responder as questões apresentadas anteriormente, mas também identificar a necessidade de desenvolvimento de métodos que auxiliem jovens através da tecnologia de jogos digitais.

Características como potencialidades, modos de funcionamento da atenção concentração, distração, dispersão criativa - focalização e dificuldades surgem durante o tempo em que o jovem está jogando, sendo identificadas durante as oficinas e o contato com os jogos. Com essa experiência, surgiu a ideia de aplicar as técnicas de jogos usando a adaptabilidade, a partir do conhecimento das características de cada jovem com suas singularidades e expressões durante contato com a tecnologia através dos jogos.

\section{Jogos Digitais}

Segundo Huizinga (1993, p. 3), o jogo "é uma atividade ou ocupação voluntária, exercida dentro de determinados limites de tempo e de espaço, segundo regras livremente consentidas, mas absolutamente obrigatórias, dotado de um fim em si mesmo, acompanhado de um sentimento de tensão e de alegria e de uma consciência de ser diferente da "vida quotidiana".

Contextualizando outras definições, tem-se a de Schuytema (2008), que define um jogo eletrônico (ou digital) como uma atividade lúdica formada por ações e decisões que resultam numa condição final. Estas ações e decisões são limitadas por um conjunto

\footnotetext{
1 O programa Rede Oficinandos na Saúde é uma experiência que reúne projetos de extensão através de uma parceria entre a Universidade Federal Rural do Semi Árido e o Centro de Atenção Psicossocial da Infância e da Adolescência (CAPSi). O programa utiliza tecnologias da informação e comunicação com o propósito de produzir modos de inserção social, cuidado e formação em saúde mental. A experiência conta com o apoio e colaboração de pesquisadores das universidades UFRGS, UFC, UNISC e UFAL e, desde o ano de 2011 é financiada pelo Ministério da Educação - PROEXT/MEC/SESU.
} 
V Congresso Brasileiro de Informática na Educação (CBIE 2016)

Anais dos Workshops do V Congresso Brasileiro de Informática na Educação (CBIE 2016)

de regras e por um universo, que, no contexto dos jogos digitais, são regidos por um programa de computador.

Prietro et al. (2005, p. 10) definem que os jogos "devem possuir objetivos pedagógicos e sua utilização deve estar inserida em um contexto e em uma situação de ensino baseados em uma metodologia que oriente o processo, através da interação, da motivação e da descoberta, facilitando a aprendizagem de um conteúdo baseados em uma metodologia que oriente o processo, através da interação, da motivação e da descoberta, facilitando a aprendizagem de um conteúdo".

Piaget (1973) esclarece que o jogo é uma atividade interessante nos processos em que uma criança constrói e avança em seus estágios de conhecimento. Ele aborda essa característica a partir do momento que a criança pode reconstruir modos de compreensão de conceitos como número, volume, entre outros investigados pelo cientista, em níveis crescentes de complexidade à medida que joga determinado jogo.

Os jogos digitais podem ajudar a melhorar o desenvolvimento, a aumentar o conhecimento e a desenvolver habilidades cognitivas. No âmbito da educação, ele pode ajudar na resolução de problemas, utilizando o pensamento estratégico e a tomada de decisão (BROM; PREUSS; KLEMENT, 2011).

Diante das definições, pode-se utilizar a de Hiuzinga (2012) e de Prietro et al. (2005) dentro de um ambiente onde essa atividade pode ser voluntária ou fazer parte de um cronograma educacional, possibilitando a interação de jovens em um único ambiente através dos jogos.

Uma plataforma contendo jogos digitais pode configurar importantes suportes teóricos e metodológicos ao campo da computação e dos estudos cognitivos, por interessar a um público cada vez maior de profissionais, pesquisadores e a comunidade em geral. Por essa razão, é de grande relevância cientifica e social o desenvolvimento de uma plataforma para jovens com transtorno de desenvolvimento e a construção de novas ferramentas analíticas para estudar os efeitos do emprego da tecnologia de jogos digitais em oficinas no ambiente de saúde mental.

\section{Jogos e Adaptabilidade}

O uso de jogos e de recursos computacionais aplicados à saúde está cada vez mais consolidado em diversas áreas. Esta circunstância está relacionada com 0 desenvolvimento de jogos aplicados à avaliação e reabilitação cognitiva. Como os jogos fazem parte do crescimento humano, uma criança pode desenvolver a percepção e, a inteligência os utilizando cotidianamente (GOMES; MOTTA; CRUZ, 2010).

Segundo Machado et al. (2012) apud Dias et al. (2015), os jogos e atividades lúdicas também apresentam aceitação pelo público quando ligadas à educação e saúde. Sendo assim, uma abordagem baseada em jogos, integrando características lúdicas a conteúdos específicos, potencializa processos cognitivos.

Andrade et al. (2004) colocam que alguns jogos com sistemas inteligentes adaptativos existentes, possuem recursos que permitem adequarem-se às necessidades de cada usuário. Essa forma de adaptar-se ou adequar-se às necessidades individuais de cada indivíduo tem como base a análise das características e o estilo de aprendizagem dos mesmos a fim de auxilia-los de forma positiva durante a construção do conhecimento. Essa construção pode ser feita a partir de sistemas computacionais 
inteligentes que possam adequar-se a essas necessidades e, assim, buscar soluções e melhorias para o aprendizado individual.

É importante destacar que, neste projeto de desenvolvimento, consideramos a aprendizagem referida à cognição inventiva, isto é, conjunto de transformações e avanços nas formas de interação e de exercício de autoria singular e coletiva na experiência dos jovens, não referidas, portanto, ao conhecimento escolar. Isto porque a plataforma proposta visa melhorar o atendimento no trabalho em saúde mental.

Segundo Araújo e Aranha (2013) apud Real, Corbellini e Michailoff (2015), os jogos podem ser utilizados para avaliar a aprendizagem. É citado pelos autores que "Jogar desenvolve a capacidade de observar regras, seguir procedimentos sistemáticos com disciplina, características que são fundamentais nas práticas científicas". Ainda é exposto que o jogo pode ajudar na atenção e, no raciocínio lógico entre outras modalidades.

Sendo assim, interfaces adaptativas podem ser usadas em softwares, aplicações e contextos que sejam necessários à interação de uma ou mais situações de um contexto e que essa interface possa adequar-se simultaneamente em uma aplicação.

\section{Cognição e Tecnologias}

Quando aplicado ao desenvolvimento cognitivo em crianças e jovens, especialmente aqueles que possuem algum transtorno no desenvolvimento, as abordagens e estudos são colocados correlacionados ao desempenho de aprendizagem, inclusão, interação com a família e no ambiente escolar. Segundo Kortmann (2013) a percepção em relação ao déficit da criança e do jovem, pode ser sanada de acordo com a inclusão e socialização da criança no âmbito estudantil, ou seja, a interação com outras pessoas e outros dispositivos podem também potencializar essa socialização.

Conforme Kastrup (2004), a cognição inventiva depende dos tipos de experiência que vêm a ter um corpo com várias habilidades sensório-motoras e essas habilidades individuais interagem em um contexto biológico e cultural mais amplo. Neste sentido, as experiências dos jovens com transtorno de desenvolvimento e a ampliação da interação que os jogos oportunizam são fundamentais para potencializar processos cognitivos.

\subsection{Tecnologias}

Segundo Morin (2010), as noções da tecnologia não podem ser isoladas do conhecimento que a produziu. O mesmo destaca a ideia de que a tecnologia é como um suporte, utilizando da simplicidade e manipulação que são geradas inconscientes pela nossa racionalidade. Seguindo esse caminho de pensamento, ele ainda sugere que "o conceito da tecnologia surge de uma relação na cultura entre a ciência, a técnica, a indústria e a sociedade".

Jack Goody (2007) refere-se às tecnologias do intelecto ao considerar que desde o surgimento da oralidade os homens já produzem um instrumento que configura modo de organização da sociedade e de modulação da cognição.

Spohr (2015), inspirada na obra de Gilbert Simondon (1958;1989) esclarece em sua tese que essa concepção da relação homem-técnica tem como fundamento todo um 
V Congresso Brasileiro de Informática na Educação (CBIE 2016)

Anais dos Workshops do V Congresso Brasileiro de Informática na Educação (CBIE 2016)

conjunto constituído pelos indivíduos, os objetos técnicos e a sociedade de modo inseparável.

\section{Características de Jovens em Saúde Mental}

Foram observadas nos jovens inseridos no CAPSi características apresentadas em três momentos: antes, durante e depois do contato com os jogos, sendo que registramos modos de coordenar gestos, ideias e emoções. Observou-se que o encontro dos jovens com os jogos promovia novas interações, principalmente porque passavam a jogar juntos, experiência esta destacada pelos profissionais do CAPSi. Surge então a possibilidade de observar melhor esse contato dos jovens com os jogos e o que a experiência nas oficinas permite observar no modo de coordenar condutas no ambiente.

As oficinas acontecem em um ambiente equipado com 08 computadores, 8 tablets e 8 câmeras fotográficas. Durante as oficinas, acontecem intervenções que ocorrem nas quintas e sextas feiras, turnos da manhã e tarde, de modo que os estudantes oficineiros, totalizando 12 alunos, e 4 pesquisadores oficineiros, interagem com grupos de 08 crianças e/ou jovens. Os sujeitos envolvidos no atendimento em saúde mental possuem de 04 a 18 anos de idade. Os diagnósticos apresentados pela instituição são de autismo, depressão ou deficiência mental, portanto temos circunstâncias de sofrimento psíquico e/ou transtornos mentais.

Familiares também participam de oficinas organizadas em outro ambiente do CAPSi, oficinas estas, que são direcionadas com artes e saúde mental. Neste estudo focaliza-se os encontros e oficinas de jogos, e, considera-se as escritas de diário de bordo que foram realizadas pelos oficineiros durante o transcurso da experiência.

A partir de uma análise que considera os estudos da cognição e a presença de uma pesquisadora deste campo do Programa Rede de Oficinandos na Saúde, pôde-se montar uma tabela contendo essas informações extraídas dos diários de bordo de oficineiros do programa durante as oficinas.

Os jovens que participaram dessa observação estão em circunstâncias como o autismo, a deficiência mental e/ou a depressão, mas nesse artigo, serão apresentadas na tabela apenas as circunstâncias de jovens com autismo, devido a necessidade de um recorte para composição da escrita. Cada jovem apresenta singularidades, mesmo quando diagnosticados om um tipo de transtorno, portanto nesta tabela indicamos apenas características que foram recorrentes em nossa experiência.

Diante do exposto, a Tabela 1 apresenta alguns elementos que foram levantados durante as oficinas e observações com jovens do Programa Rede Oficinandos na Saúde.

Tabela 1. Tabela contendo as características dos jovens sobre os jogos já utilizados, dispositivos presentes nos jogos já conhecidos e dispositivos a estarem presentes na plataforma.

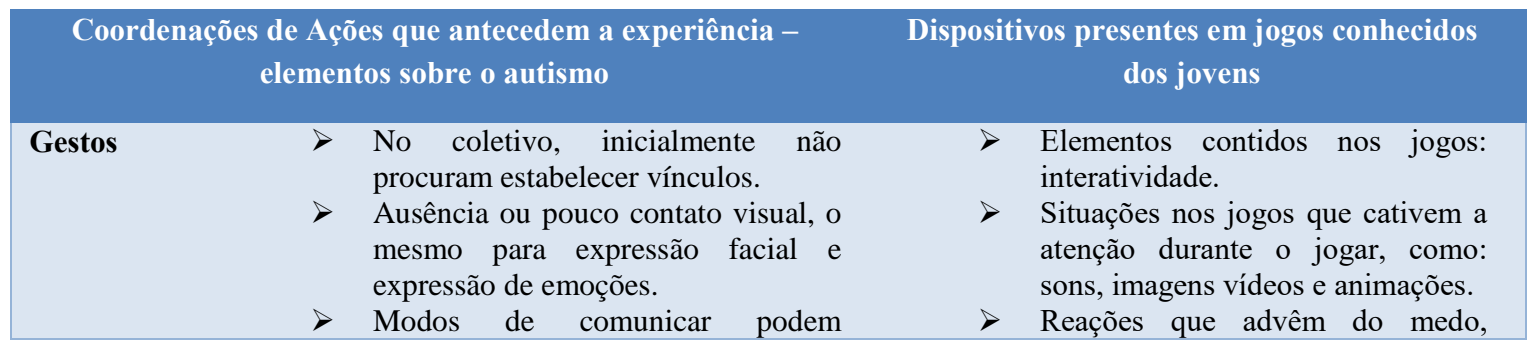


V Congresso Brasileiro de Informática na Educação (CBIE 2016)

Anais dos Workshops do V Congresso Brasileiro de Informática na Educação (CBIE 2016)

\begin{tabular}{|c|c|c|}
\hline & $\begin{array}{l}\text { acontecer sem a fala. Repetição de } \\
\text { ações, palavras (quando já iniciam a } \\
\text { falar) e na escolha de objetos. } \\
\text { Abrem e fecham os jogos } \\
\text { inicialmente, sem explorar. A alegria } \\
\text { pode vir na forma de bater com as } \\
\text { pontas dos dedos no alto da cabeça, } \\
\text { como a comemorar o que fazem ou } \\
\text { no sorriso, ou no olhar } \\
\text { alegre/sorridente, ou ainda com sons, } \\
\text { modos de dizer. } \\
\text { O medo pode vir na forma de tapar } \\
\text { os ouvidos, chorar, afastar-se. } \\
\text { Inquietações podem acontecer e, em } \\
\text { alguns casos, temos o sentar no chão, } \\
\text { repetição de gestos com um objeto, } \\
\text { esconder-se atrás da porta. }\end{array}$ & $\begin{array}{l}\text { como o choro, repetições de gestos } \\
\text { com determinado objeto. Percebe- } \\
\text { se, na maioria dos casos } \\
\text { vivenciados, que acontecia com o } \\
\text { volume excessivo do áudio. Nesse } \\
\text { caso, o controle do volume, de } \\
\text { acordo com cada jovem, deve ser } \\
\text { modificado para evitar essas } \\
\text { reações. } \\
\text { Outras reações de medo partiam de } \\
\text { jogos com violência excessiva ou } \\
\text { cenas de terror que os jovens } \\
\text { tinham acesso fora do ambiente do } \\
\text { CAPSi. }\end{array}$ \\
\hline Ideias & $\begin{array}{l}\text { Mostram o interesse por objetos } \\
\text { específicos, vídeos, jogos e podem } \\
\text { permanecer neles durante longo } \\
\text { período. } \\
\text { O interesse se mostra através do } \\
\text { pedido para jogar, por vezes } \\
\text { apontando para aqueles dispositivos } \\
\text { que vem experimentando, ou na } \\
\text { forma de palavras, pequenas frases. }\end{array}$ & $\begin{array}{l}\text { Elementos contidos nos jogos: } \\
\text { personagens conhecidos por eles. } \\
\text { São atraídas pela jogabilidade, o } \\
\text { ato de jogar com praticidade } \\
\text { utilizando um dispositivo como o } \\
\text { tablet. }\end{array}$ \\
\hline Emoções & $\begin{array}{l}\text { Observamos um estranhamento na } \\
\text { interação com elementos que podem } \\
\text { provocar sustos, tensões, medos no } \\
\text { ambiente, assim como podem } \\
\text { alegrar. } \\
\text { Observa-se o receio, o temor e o } \\
\text { medo. Estas emoções têm relação } \\
\text { com diferentes elementos: sons, } \\
\text { cores, imagens de objetos. } \\
\text { Observamos a vibração e alegria } \\
\text { desde o encontro com um fazer que } \\
\text { parece possível, a fase de um jogo, o } \\
\text { simples iniciar a jogar, mas estas } \\
\text { emoções podem se alterar, na relação } \\
\text { com as circunstâncias do ambiente e } \\
\text { do próprio sujeito. }\end{array}$ & $\begin{array}{l}\text { O impacto inicial dos jogos que } \\
\text { foram inseridos nas oficinas, pode } \\
\text { de certa forma causar um } \\
\text { estranhamento. Mas depois do } \\
\text { primeiro contato, é gerado um } \\
\text { interesse pelos jogos. } \\
\text { As reações em suas emoções, } \\
\text { podem ser auxiliadas com a função } \\
\text { de controlar a iluminação da } \\
\text { imagem, o volume do som, o } \\
\text { auxílio de um monitor (oficineiro) } \\
\text { durante o jogar. }\end{array}$ \\
\hline \multicolumn{2}{|c|}{$\begin{array}{l}\text { Transformações nas coordenações de ações } \\
\text { Coordenações de ações novas e emergentes - autismo }\end{array}$} & $\begin{array}{l}\text { Dispositivos a estarem presentes na } \\
\text { Plataforma de Jogos Digitais }\end{array}$ \\
\hline Gestos & $\begin{array}{l}\text { Atenção endereçada às imagens e aos } \\
\text { movimentos presentes nos jogos. } \\
>\quad \text { Exploram diferentes jogos no ambiente. } \\
>\quad \text { Saem de sua cadeira e lançam o olhar } \\
\text { para o que os outros fazem. } \\
>\quad \begin{array}{l}\text { Passam a experimentar o jogar junto } \\
\text { com o outro. }\end{array}\end{array}$ & $\begin{array}{l}\text { Elementos da plataforma } \\
>\quad \text { Animação do jogo. } \\
>\quad \text { Variedade de jogos em um único } \\
\text { ambiente. } \\
>\quad \text { Interatividade de forma adaptativa. } \\
>\quad \text { Várias fases no jogo aumentando os } \\
\text { desafios. }\end{array}$ \\
\hline Ideias & 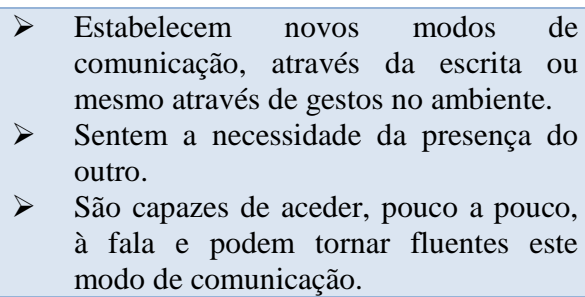 & 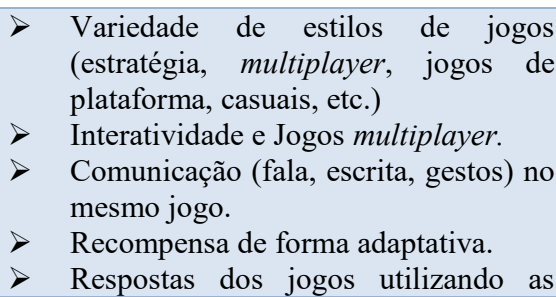 \\
\hline
\end{tabular}


V Congresso Brasileiro de Informática na Educação (CBIE 2016)

Anais dos Workshops do V Congresso Brasileiro de Informática na Educação (CBIE 2016)

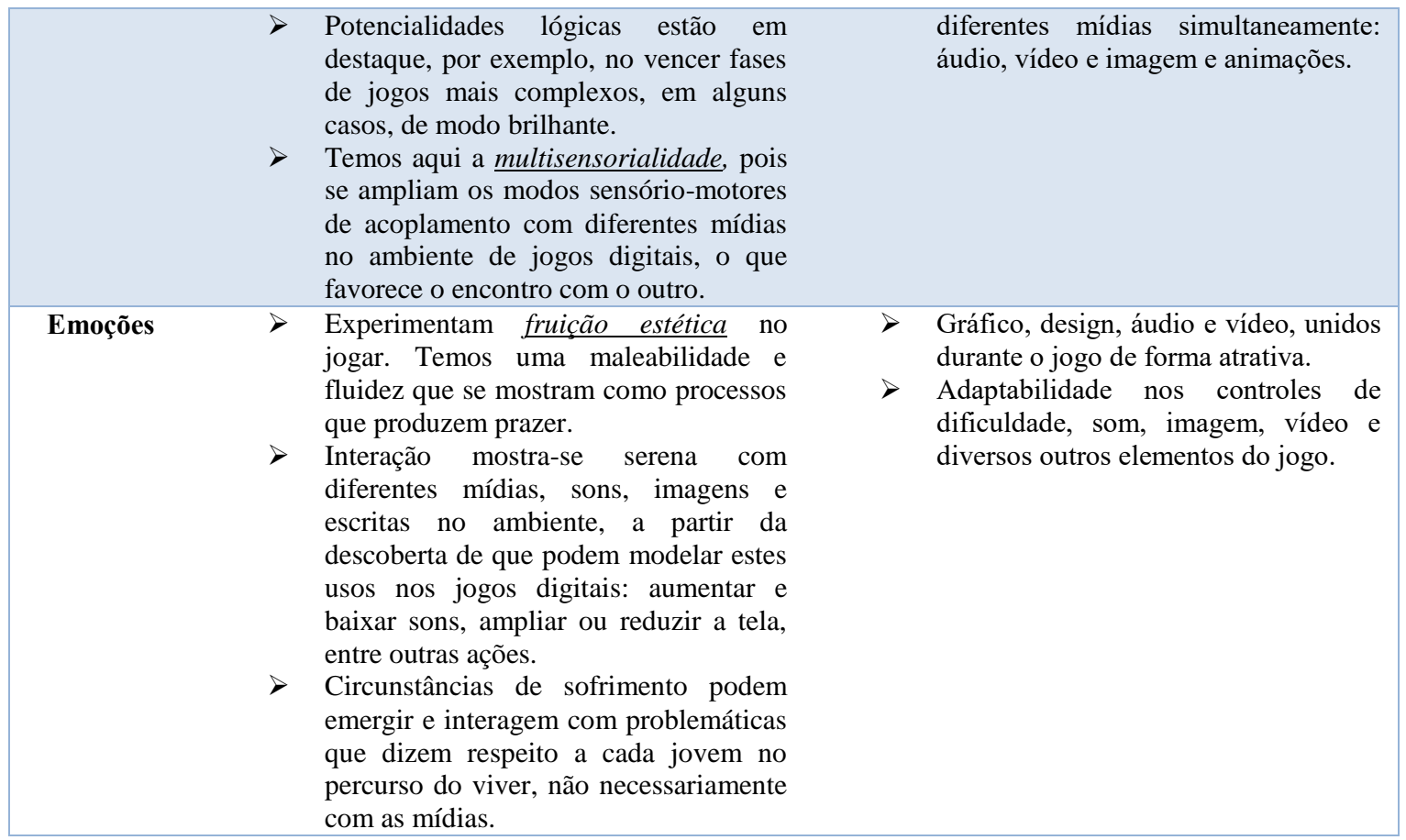

Os resultados dessa tabela se colocam como uma base para entender e elencar quais elementos dos jogos são atrativos para os jovens inseridos no CAPSi que participam das oficinas. E então, se dará continuidade ao desenvolvimento diante dessas informações, tanto sobre modos de coordenar condutas dos jovens, como sobre elementos presentes nos jogos.

\section{Uma Plataforma para Potencializar a Cognição de Jovens com Transtorno de Desenvolvimento}

Segundo Andrade et al. (2004), os jogos são desenvolvidos a partir de objetivos psicopedagógicos consolidados e podem ser utilizados como uma extensa gama de capacidades cognitivas, como também, em sistemas inteligentes adaptativos, os quais podem possuir e fornecer recursos adaptáveis às necessidades de cada usuário.

A proposta de uma plataforma contendo jogos com funções adaptativas surge a partir da necessidade de desenvolver ferramentas que tomam como base as características individuais de jovens em situações e circunstancias de transtorno no desenvolvimento cognitivo.

A plataforma está sendo desenvolvida em jogos multiplataforma utilizando a Unity 2D, a qual dá suporte as linguagens C\# e JAVA. A escolha se deu pela compatibilidade com outras tecnologias e aceitação em diversos dispositivos. A utilização de jogos em uma linguagem simples e objetiva, em uma interface que atraia a atenção dos jovens, possibilita acompanhar os interesses dos jovens, e potencializar as ações de jovens com algum transtorno de desenvolvimento.

O desenvolvimento se encontra na fase de avaliação do protótipo e melhorias quanto à técnica adaptativa que se adeque aos jogos já desenvolvidos. Existe uma técnica de balanceamento dinâmico de dificuldade que está sendo analisada, que, de acordo com Andrade et al. (2005), pode ser utilizada para alterar parâmetros, cenários 
V Congresso Brasileiro de Informática na Educação (CBIE 2016)

Anais dos Workshops do V Congresso Brasileiro de Informática na Educação (CBIE 2016)

e/ou comportamentos durante o jogo, a partir do desempenho e interesse do jogador durante a execução do jogo.

Segundo Koster (2010), o balanceamento de dificuldade pode ser usado também como ajuste de dificuldade, e baseia-se, como Andrade at al. (2005) citou, em alterar parâmetros, cenários e/ou comportamentos do jogo. Os benefícios que os mesmos apresentaram, tendo em vista as reações do jogador durante o jogo, é fazer com que o jogador não se sinta frustrado de acordo com o seu desempenho em níveis mais difíceis ou se sinta entediado se o nível ficar fácil demais.

Pretende-se então aplicar essa técnica de balanceamento de dificuldade, junto com os dispositivos que chamam a atenção dos jovens, de modo que esses dispositivos possam adequar-se a seus gestos, ideias e emoções (perdas, ganhos, dificuldades, desistência) durante os jogos. Um exemplo seria quando um jogador em circunstancia de autismo estiver jogando e uma característica que chamou sua atenção foi a interatividade com outros jogadores e em algum momento não houve interatividade, de modo que seu desempenho não foi satisfatório para ele mesmo, então, no próximo momento do jogo (fase do jogo) será ativado o modo interativo novamente para que o jogador prossiga jogando.

Segundo Silva (2015), a definição das dificuldade é subjetiva e diversos aspectos podem ser levados em consideração para avaliá-la e medi-la. Nesse caso, serão conceituadas as características para verificar as dificuldades durante os jogos précadastradas e serão acompanhadas de acordo com o desempenho e interesse do jogador em cada jogo.

A validação se dará junto com os jovens inseridos no CAPSi na utilização da plataforma e terá a ajuda de uma equipe de profissionais que atuam também junto ao CAPSi. Através de oficinas e testes com a plataforma, serão analisadas as transformações que acontecem no modo de coordenar condutas na experiência dos jovens com a plataforma. Está sendo feita uma análise das reações: antes, durante e depois do jogo, melhorando a Tabela 1, apresentada anteriormente.

A Figura 1 apresenta alguns jogos que estão inseridos na plataforma, os mesmos estão sendo finalizados para adicionar técnicas adaptativas.
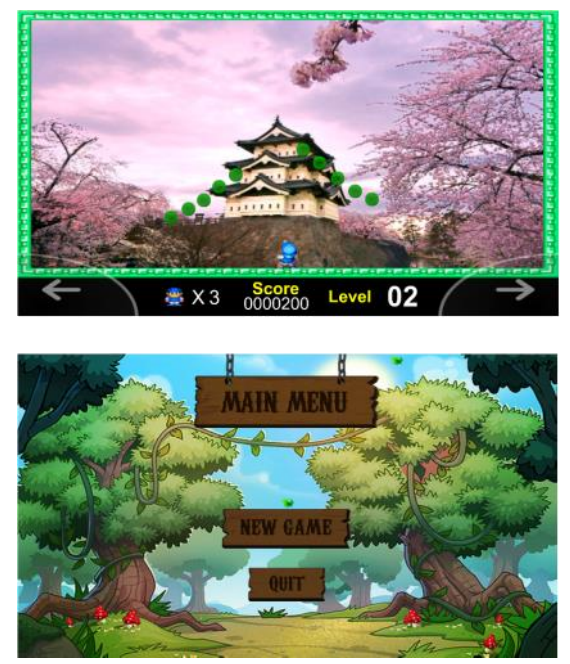
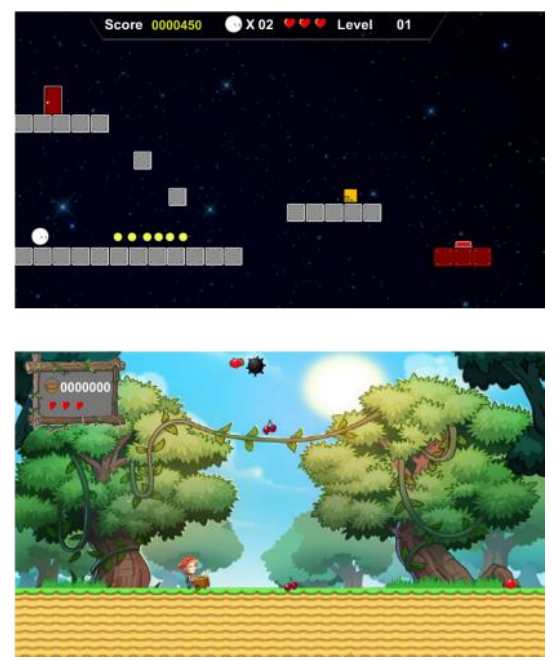
V Congresso Brasileiro de Informática na Educação (CBIE 2016)

Anais dos Workshops do V Congresso Brasileiro de Informática na Educação (CBIE 2016)

Figura 1. Jogos em desenvolvimento contidos na plataforma.

\section{Considerações Finais}

$\mathrm{O}$ artigo apresenta conceitos de jogos digitais, cognição e tecnologias que se alocam, como base para o desenvolvimento de uma plataforma com funções e técnicas adaptativas que atendam e auxiliem jovens com transtorno do desenvolvimento.

Como trabalhos futuros têm-se a finalização da plataforma, de forma que atue com a recomendação durante a aplicação no ambiente; a validação junto aos jovens do CAPSi e a expansão da plataforma para outros dispositivos, além da inclusão de outras técnicas adaptativas em pesquisa.

\section{Referências}

Andrade, L. C. V.; Araujo, C.; Moratori, P. B..; Lima, J. C.; Franco, P.; Soares, A. (2004) "Mapa do Zoológico - Captura Cognitiva para Disfunção Executiva". XV SBIE - Simpósio Brasileiro de informática na Educação, Manaus.

Andrade, G.; Ramalho, G.; Santana, H. \& Corruble, V. (2005) "Extending reinforcement learning to provide dynamic game balancing". Em Proceedings of the Workshop on Reasoning, Representation, and Learning in Computer Games, 19th International Joint Conference on Artificial Intelligence (IJCAI).

Araujo, G. G.; Aranha, E. H. da S. (2013) "Avaliação formativa da aprendizagem com instrumentação em Jogos digitais: Proposta de um framework conceitual". In. ANAIS DO XIX WORKSHOP DE INFORMÁTICA NA ESCOLA. São Paulo. Disponível em: < http://www.brie.org/pub/index.php/wcbie/article/view/2688>

Brom, C., Preuss, M.; Klement, D. (2011) "Are educational computer micro-games engaging and effective for knowledge acquisition at high-schools? A quasiexperimental study”. Computers \& Education, 57(3), p.1971-1988.

Caliman, L. V. (2008) "O TDAH: Entre as Funções, disfunções e Otimização da atenção". Psicologia em Estudo, Maringá, v. 13, n. 3, p.556-566, 01 jul. Disponível em: <http://www.scielo.br/pdf/pe/v13n3/v13n3a17.pdf>. Acesso em: 16 jun. 2015.

De-Nardin, M. H.; Sordi, R. O. (2008) "Aprendizagem da atenção: uma abertura à invenção". Revista Iberoamericana de Educación, Rio Grande do Sul, v. 4, n. 47, p.111, 10 nov. Disponível em: <http://www.rieoei.org/deloslectores/2559Sordiv2.pdf > Acesso em: 26 jun. 2015.

Dias, J. D., et al. (2015) "Desenvolvimento e avaliação de um jogo educacional digital para enfrentamento da obesidade infantil". In. ANAIS DOS WORKSHOPS DO IV CONGRESSO BRASILEIRO DE INFORMÁTICA NA EDUCAÇÃO (CBIE 2015). DOI: $10.5753 /$ cbie.wcbie.2015.110

Gomes, D. S. M. G.; Motta, C. L. R.; Cruz, A. J. O. (2010) "Sistema Integrado para Construção de Inferências Nebulosas Aplicáveis a Jogos Psicopedagógicos". Revista Brasileira de Computação Aplicada. v.2, n. 2, set. DOI: 10.5335/rbca.2010.015.

Goody, J. (2007). "Pouvoirs et savoirs de l'écrit”. Trad. de l'anglais par Claire Maniez ; coordination par Jean-Marie Privat, Paris, La Dispute. 
V Congresso Brasileiro de Informática na Educação (CBIE 2016)

Anais dos Workshops do V Congresso Brasileiro de Informática na Educação (CBIE 2016)

Huizinga, J. (1993) "Homo Ludens: o jogo como elemento da cultura". 4. ed. Tradução João Paulo Monteiro. São Paulo: Perpectiva.

Huizinga, J. (2012) "Homo ludens”. São Paulo: Perspectiva.

Kastrup, V. (2004) “A aprendizagem da atenção na cognição inventiva". Psicologia \& Sociedade, Rio de Janeiro, v.16, n.3, set/dez. Disponível em: < http://www.scielo.br/pdf/psoc/v16n3/a02v16n3.pdf

Kortmann, G. M. L. (2013) “Aprendizagens da Criança Autista e suas Relações Familiares e Sociais: Estratégias Educativas. Monografia de conclusão do Curso de Especialização em Neuropsicologia". Universidade Federal do Rio Grande do Sul Instituto de Psicologia. Porto Alegre, jan.

Koster, R. (2010) “Theory of fun for game design”. O'Reilly Media, Inc.

Machado, L. S., et al. (2011). "Serious games baseados em realidade virtual para educação médica". Rev. bras. educ. méd, 35(2), 254-262.

Maturana, H.; Varela, F. (2001) "A árvore do conhecimento: as bases biológicas da compreensão humana." São Paulo: Edoitora Palas Athena.

Monte, W. S. do. (2014) "Oficinando com jovens: análise de processos de atenção na experiência com jogos digitais". Dissertação (Mestrado em Ambiente, Tecnologia e Sociedade) - Universidade Federal Rural do Semi-Árido. Mossoró/RN.

Morin, Edgar. (2010) "Ciência com consciência". 13. ed. Rio de Janeiro : Bertrand Brasil.

Piaget, J. (1973) “A formação do símbolo na criança”. Rio de Janeiro: Zanyhar.

Prietro, L. M. et al. (2005) "Uso das Tecnologias Digitais em Atividades Didáticas nas Séries Iniciais". Renote: revista novas tecnologias na educação, Porto Alegre, v. 3, n. 1, p.1-11.

Real, L. M. C.; Corbellini, S.; Michailoff F. (2015) "Jogos online: ferramentas nas Intervenções Psicopedagógicas". In. ANAIS DO XXI WORKSHOP DE INFORMÁTICA NA ESCOLA 2015, Rio Grande do Sul. Disponível em: http://www.br-ie.org/pub/index.php/wie/issue/view/128

Schuytema, P. (2008) "Design de games: uma abordagem prática”. São Paulo: Cengage Learning.

Simondon, G. (2008) "Du modes d'existence des objets techniques”. Paris: Aubier.

Spohr, F. S. (2015) "Cadernos, Pincéis e Netbooks: Modulações Tecnológicas em Uma Escola de Rede Pública de Ensino Básico". Tese (Doutorado) -- Universidade Federal do Rio Grande do Sul, Centro de Estudos Interdisciplinares em Novas Tecnologias na Educação, Porto Alegre, BR - RS.

Sternberg, R. J. (2010) "Psicologia Cognitiva”. 5 ed. São Paulo: Cengage Learning.

Silva, M. P. (2015) "Inteligência Artificial Adaptativa para Ajuste Dinâmico de Dificuldade em Jogos Digitais”. Dissertaçãao (Mestrado) -- Universidade Federal de Minas Gerais.

Varela, F. (1988). "Conhecer: as ciências cognitivas tendências e perspectivas”. Lisboa: Instituto Piaget. 